\title{
Optimal Over Current Relay Coordination of a Real Time Distribution System with Embedded Renewable Generation
}

\author{
A. Kamal ${ }^{1 *}$, S. Sankar ${ }^{2}$ and R. Soundarapandian ${ }^{3}$ \\ 'Department of EEE, St.Peter's University, Avadi, Chennai, India; ak2_anvi@yahoo.co.in \\ 2Department of EEE, Panimalar Institute of Technology, Chennai, India; ssankarphd@yahoo.com \\ 32Department of EEE(Marine), AMET University, Kanathur-603112, India; rsoundar88@gmail.com
}

\begin{abstract}
Problems associated with mal operation of relays or Non operation of relays results in larger outage time and huge commercial loss in process industries and power plants. This paper proposes a new technique for set-ting all Over Current (OC) relays in substations, process industries with cogeneration and distribution system with Embedded Renewable Generation. This technique is more suitable where there is a drastic change in the fault current based on the network topology and configuration. It is based on an appropriate equivalent circuit of the power grid to estimate the required short-circuit currents. This technique is used in setting the OC relays of an IEEE 30 Bus system, Real time steel industry and a Real time distribution system with Embedded Renewable Generation. Plug setting, Time Dial setting and Type of curve are optimized which results in better coordination in terms protection of components and maintaining the time interval between down stream and upstream relays. There is a significant reduction in fault clearing time which reduces the damage and enhance the stability. In addition, it also prevents all the mal operation of relays and nuisance tripping. This concept will helpful in developing the auto setting relays in the future. Process industries with cogeneration and medium voltage transmission system are potential application for proposed methodology.
\end{abstract}

Keywords: Adaptive Setting, Automatic Setting, Distribution System, Embeded Renewable Generation, Over Current relays, Relay Coordination

\section{Introduction}

Conventionally Over Current (OC) relay settings are provided based on full load current of power system components. Time Dial Setting (TDS) and Type of curve are chosen to ensure that the coordination with the downstream relays. This conventional procedure for setting the relays went well for a long time. However, introduction of Embedded Renewable Generation, Cogeneration in plants in process industries and islanding from the grids, Change in the Grid Topology etc. results in the drastic change in the fault current. This leads to problems like nuisance tripping of relays, improper coordination or longer time taken to operate the relays for a fault. Situation got worse in the continuous addition of renewable generation, most sophisticated grid islanding schemes, Energy efficient motors which draw's high starting current, technological advancements in controlled switching for transformer and reactor to reduce the inrush current etc made the conventional of relay setting obsolete. These technological advancements along with new feature in the modern numerical relays provide a better platform to coordinate the relays to reduce the operating time of relay, prevent the nuisance tripping and ensure the coordination between the relays in all the grid topologies.

Over current Relays utilized in power systems protection as economical protective devices. Over current relays are used as main protection devices in Low Voltage Radial systems and as backup relays to distance and

\footnotetext{
${ }^{*}$ Author for correspondence
} 
differential in High voltage interconnected transmission and sub-transmission system.

Over current Relays are categorized as Instantaneous, definite time and inverse time relays. Modern numerical relays from famous manufacturers like ABB, Areva, GE, Siemens etc has three stages of Protection. Stage $1 \& 2$ shall be either Inverse curve or definite time whereas Stage 3 is Instantaneous without any time delay. In addition, these relays have additional feature of multiple setting depending the digital input to the relay which may corresponds to particular topology of grid conditions. Moreover, these relays have inrush or starting multipliers which may be effectively used to prevent the maloperation of relays during motor starting or transformer charging. In addition to conventional curves such as Normal Inverse (NI), Very Inverse (VI), Extremely Inverse (EI), Long Time Inverse (LTI), Standard Inverse (SI) etc. relays also have the feature of developing their own user defined curves based on the user requirements. All these features available in the modern relay are effectively utilized with sophisticated software program to reduce the fault clearing time and prevent the nuisance tripping of the relays.

\section{Over Current Relays Coordination}

\subsection{CT Selection}

Proper selection and sizing of Current Transformers are first important step in over current relay coordination ${ }^{1}$ Proposes full adaptive technique to optimal coordination of relays; however, the CT ratio selected is not correct. CT ratio should be selected based on the Full load current of component with the overload margin. However, the Primary CT rating is less than the full load current of the components in many cases ${ }^{1,2}$.

\subsubsection{Stage: 1/2 (Inverse Definite Minimum Time Delay - IDMT Relay - 51)}

\section{Pickup up Setting or Plug Setting}

Plug setting for inverse relays shall be selected based on the maximum possible load current and over load margin. In HV substation this depends on the worst case power-flow current with some future margin. Dynamic setting for various network topology is discussed in ${ }^{3,4}$. However, this methodology lacks in detection of the change in topology.
Paper $^{5}$ attempts to overcome the drawbacks of ${ }^{3,4}$ however it needs a complicated communication channel.

\section{Time Dial Setting (TDS) or Time Multiplier Setting (TMS)}

Choosing TDS is more involved task which provides the necessary coordination with downstream relays ${ }^{6-8}$. This depends on many factors including maximum fault current, minimum fault current, Starting Current, Inrush Current, Through fault current, Type of curve selected etc.

\subsection{Curve Selection}

Selection of curve for the relay is also involved task. Conventionally Normal Inverse or Stand Inverse is selected for plain feeders and Extremely Inverse is used for Transformer Feeders and Motor Feeders.

Gokhale, Ukil and Uthitsunthorn ${ }^{11-13}$ propose some artificial intelligent techniques to coordinate the relays based on various topologies and contingencies. However, these methods have not included any feature of the relay which has multiple stages.

\subsubsection{Stage: 2 (Definite Time Delay - DT Relay - 5)}

\section{Pickup up Setting or Plug Setting}

Plug setting for Definite Time relays depends upon whether time discrimination is adopted or not. If time discrimination is not used i.e., Definite Time is set as minimum time then the pickup setting shall be higher than the starting or inrush or through fault current. However, present modern numerical relays provides many options related to starting and inrush and hence pickup setting can be lowered in normal operating condition which reduces the damage. i.e., even when there is fault with minimum short circuit current this options enable to fall in the Definite Time region of the relay characteristics which falls in Inverse characteristics of the relay in conventional setting. This result in significant reduction of fault clearing time and hence the damage.

\section{Time Setting (TS)}

Proper Time discrimination is used if the relay is used to coordinate with the downstream relays. Otherwise the minimum time delay available in the relay has been used. 


\subsubsection{Stage: 3 (Instantaneous stage - 50)}

\section{Pickup up Setting}

Pickup setting shall be higher than the starting or inrush or through fault current. However, present modern numerical relays provides many options related to starting and inrush and hence pickup setting can be lowered in normal operating condition which reduces the damage. i.e Even when there is fault with minimum short circuit current this options enable to fall in the instantaneous region of the relay characteristics which falls in Inverse characteristics of the relay in conventional setting. This result in significant reduction of fault clearing time and hence the damage.

Earth fault settings also Similar to the over current relay setting except the below facts.

Plug settings are based on the unbalanced current in residual connected type current transformers and minimum possible setting shall be adopted in Core Balancing Current Transformers

Earth fault current depends on the type of earthing (Solid, Resistance Earthed) and hence care shall be taken to ensure the fault current available.

Earth fault current also depends on the winding configuration. For an example of fault on the star side of the Delta - Star transformer, the same will not be reflected in the Delta side and hence the same need not be coordinated.

\subsection{Relay Characteristics to IEC (60255)}

\begin{tabular}{lc}
\hline Relay characteristics & Equation(IEC 60255) \\
\hline Standard inverse(SI) & $\mathrm{T}=\mathrm{TMS} \times \frac{0.4}{I_{r}^{0.02}-1}$ \\
Very Inverse (VI) & $\mathrm{T}=\mathrm{TMS} \times \frac{13.5}{I_{r}-1}$ \\
Extremely Inverse (EI) & $\mathrm{T}=\mathrm{TMS} \times \frac{80}{I_{r}^{1}-1}$ \\
Long time earth fault & $\mathrm{T}=\mathrm{TMS} \times \frac{120}{I_{r}-1}$ \\
\hline
\end{tabular}

\subsection{Grading Margin}

The current and time settings selection shall start at the load end and worked back towards the power source.
Grading margins between protection relays shall be typically as follows:

The grading margin shall be 0.4 to $0.5 \mathrm{~s}$ but can be reduced such that the total minimum time at any level does not exceed 2.5s. However, as microprocessor based numerical relays are used. The grading margin considered is $0.25 \mathrm{~s}$ to the extent possible.

$$
\begin{aligned}
& (\mathrm{Er} 1+\mathrm{Er} 2+\mathrm{Ect}) \times \mathrm{T} / 100+\mathrm{Tcb}+\mathrm{T} 0+\mathrm{Ts} \\
& =(5+5+5) \times 0.25 / 100+0.1+0.02+0.03 \\
& =0.2175<0.25 \mathrm{~s}
\end{aligned}
$$

Where,

$$
\begin{array}{ll}
\text { Er1, Er2 = } & \text { Relay Timing Errors } \\
\mathrm{Ect} & =\text { CT Error } \\
\mathrm{T} & =\text { Nominal Operating time of relay nearest } \\
& \text { to the fault } \\
\mathrm{Tcb} & =\text { Circuit Breaker Opening time } \\
\mathrm{T} 0 & =\text { Relay Overshoot time } \\
\mathrm{Ts} & =\text { Safety Margin }
\end{array}
$$

\subsection{Modeling of the System}

IEEE 30 Bus system and Real time steel industry are modeled based on the data available in the ${ }^{9,10}$ respectively. Real time distribution system with Embedded Renewable Generation is modeled based on the Single Line Diagram (SLD) provided in Figure 1. This system consist of $250 \mathrm{KW}$ Wind Turbine Generators of Pioneer Wincon Make, 600kW Doubly Fed Induction Generator of Suzlon Make and 850kW Doubly Fed Induction Generator of Gamesa Make.

\subsection{Short Circuit Studies}

Short Circuit studies are performed for all three systems considered using Electrical Transient Analysis Program (ETAP) software and the short circuit currents are tabulated in Table 1, 2 \& 3 respectively. Short Circuit study is carried out based on IEC 60909 with the $C$ factor 1.0. Short Circuit study have been carried out with various operating conditions, Grid Topologies and with and Without Cogeneration, With cogeneration alone, with and Without Embedded Renewable Generation. There is significant change in the fault current in various cases. Maximum Fault Current, Minimum Fault Current and other significant case short circuit results alone indicated in the Table 1, 2 \& 3 .

Maximum Fault Current and Minimum Fault Current at various buses are graphically indicated in Figure $2 \& 3$ for IEEE 30 bus system, Real Time Steel Industry and Real Time Distribution System respectively. 


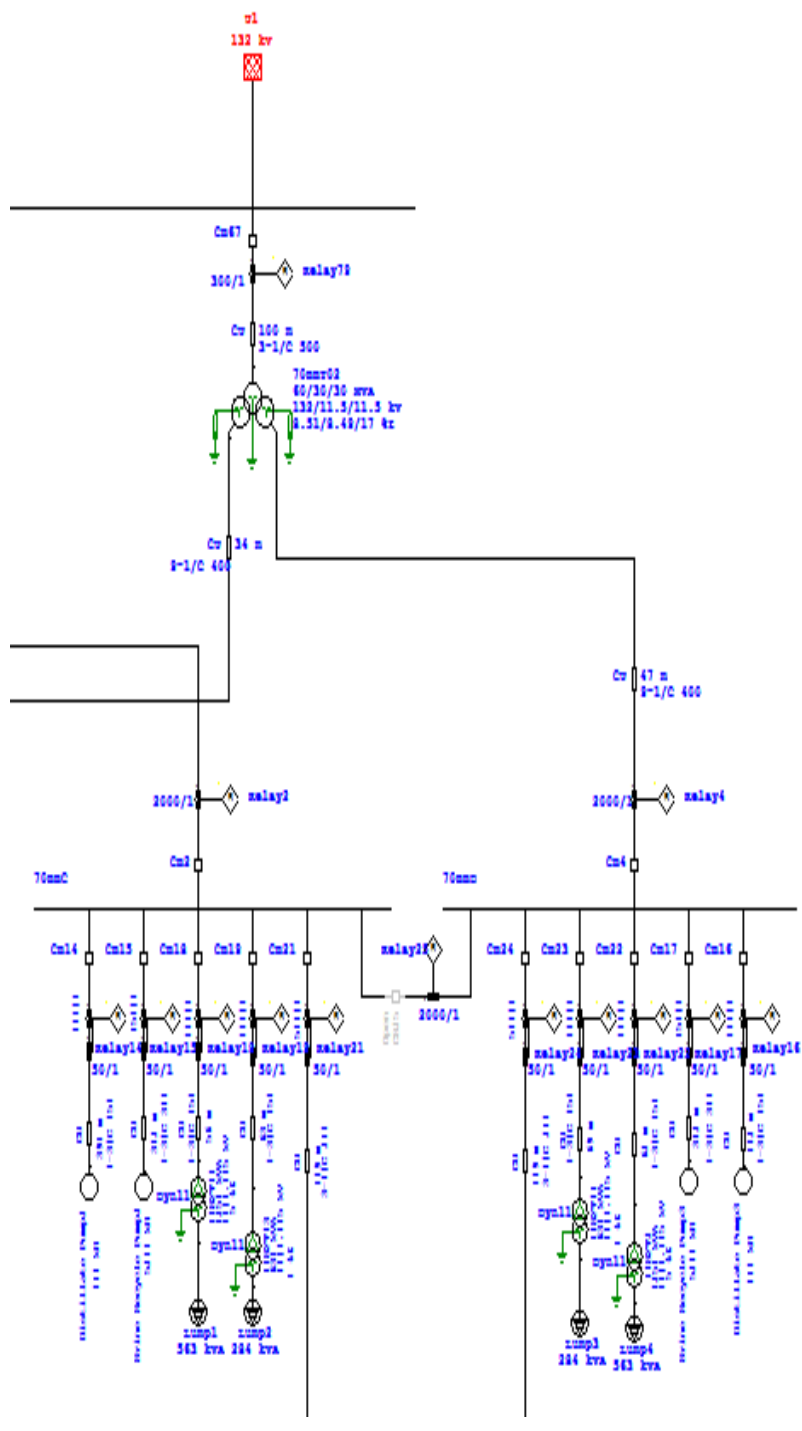

Figure 1. Single line diagram of real time distribution system with embedded renewable generation.

Table1. Fault current at various buses real time distribution system with embedded renewable generation

\begin{tabular}{lc}
\hline Bus & $\begin{array}{c}\text { Fault Current } \\
\text { In kA }\end{array}$ \\
\hline Bus 1 & 8.32 \\
Bus 2 & 5.45 \\
Bus 3 & 7.5 \\
Bus 4 & 9.32 \\
Bus 5 & 11.5 \\
Bus 6 & 10.5 \\
Relay 7 & 15.2 \\
\hline
\end{tabular}

Table 2. Fault current at various buses real time steel industry

\begin{tabular}{lc}
\hline Bus & $\begin{array}{c}\text { Fault Current } \\
\text { In kA }\end{array}$ \\
\hline Bus 1 & 25.64 \\
Bus 2 & 30.4 \\
Bus 3 & 25.75 \\
Bus 4 & 30.4 \\
Bus 5 & 25.55 \\
Bus 6 & 29.6 \\
\hline
\end{tabular}

Table 3. Fault current at various buses real time distribution system with embedded renewable generation

\begin{tabular}{lc}
\hline Bus & $\begin{array}{c}\text { Fault Current } \\
\text { In kA }\end{array}$ \\
\hline Bus 1 & 8.95 \\
Bus 2 & 11.6 \\
Bus 3 & 2.08 \\
Bus 4 & 2.6 \\
Bus 5 & 8.95 \\
Bus 6 & 11.8 \\
\hline
\end{tabular}

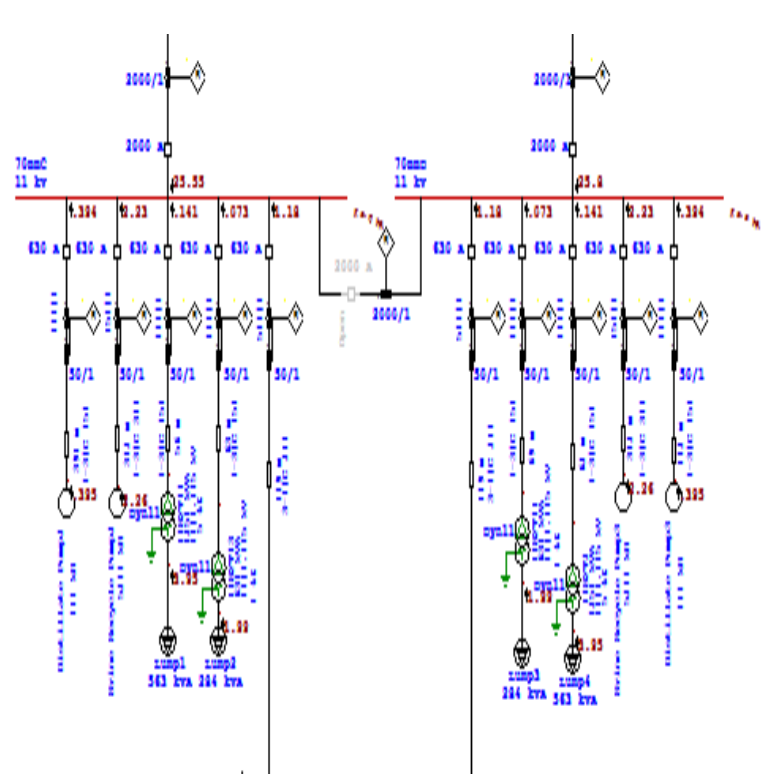

Figure 2. Fault current at various buses real time distribution system with embedded renewable generation. 


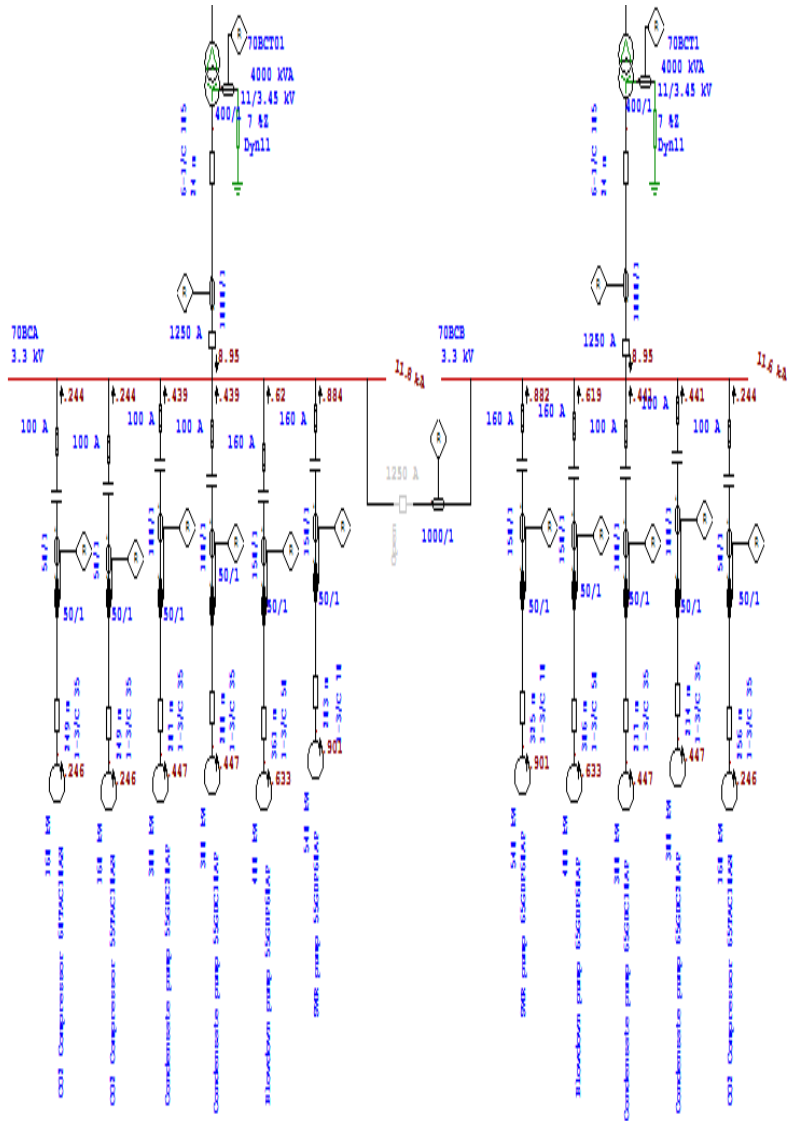

Figure 3. Fault current at various buses real time steel industry.

\section{Simulation and Results}

\section{IEEE 30 BUS System}

\subsection{Relay operating time table for a fault}

\begin{tabular}{lcc}
\hline Relay & $\begin{array}{c}\text { Fault Current } \\
\text { In kA }\end{array}$ & $\begin{array}{c}\text { Operating Time } \\
(\mathrm{ms})\end{array}$ \\
\hline Relay 1 & 8.32 & 875 \\
Relay 2 & 5.45 & 787 \\
Relay 3 & 7.5 & 603 \\
Relay 4 & 9.32 & 287 \\
Relay 5 & 11.5 & 293 \\
Relay 6 & 10.5 & 40 \\
Relay 7 & 15.2 & 40 \\
\hline
\end{tabular}

\subsection{Relay Curve Graphs}

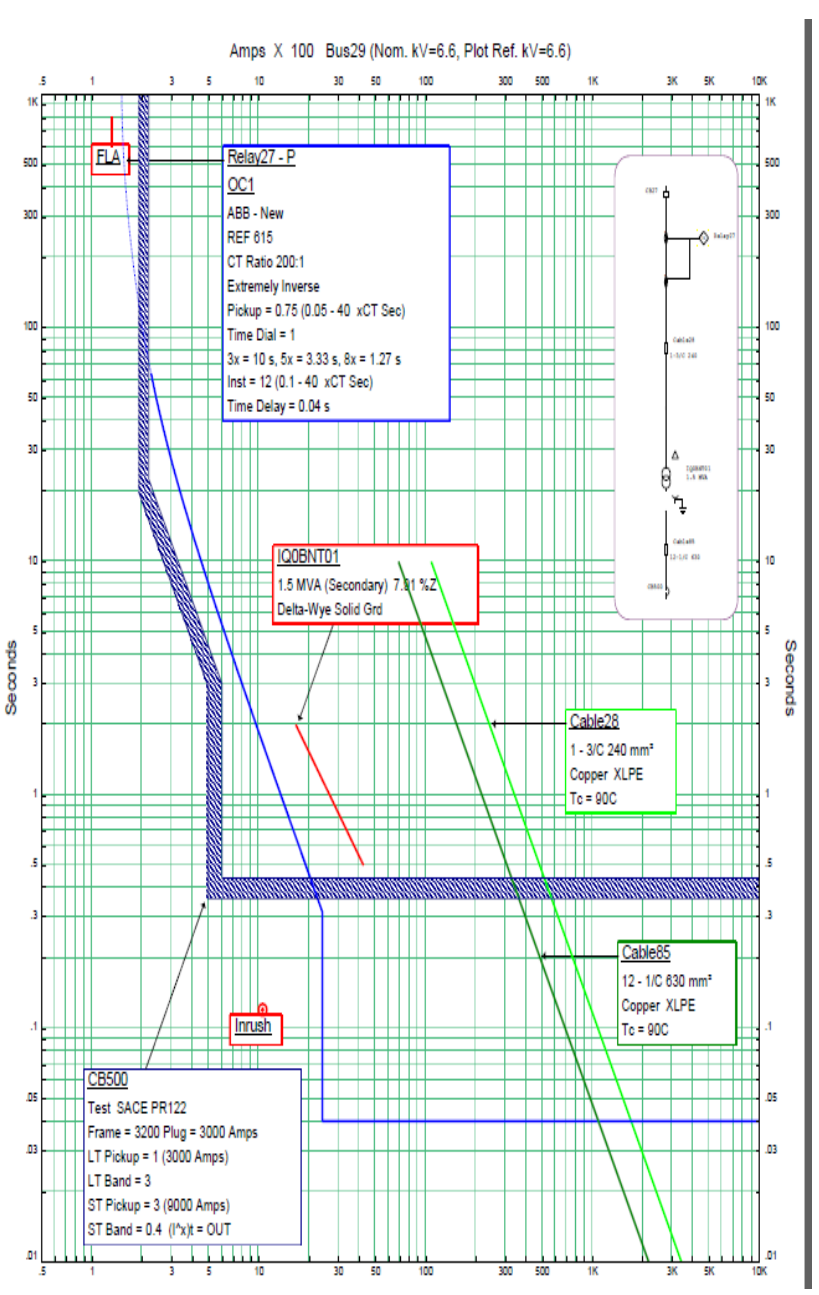

\section{Real Time Steel Industry}

Relay Setting Table

Relay operating time table for a fault

\begin{tabular}{lcc}
\hline Relay & $\begin{array}{c}\text { Fault Current } \\
\text { In kA }\end{array}$ & $\begin{array}{c}\text { Operating Time } \\
(\mathbf{m s})\end{array}$ \\
\hline Relay 1 & 25.64 & 40 \\
Relay 2 & 30.4 & 40 \\
Relay 3 & 25.75 & 320 \\
Relay 4 & 30.4 & 323 \\
Relay 5 & 25.55 & 547 \\
Relay 6 & 29.6 & 556 \\
Relay 7 & 25.64 & 823 \\
\hline
\end{tabular}




\section{Relay curve graphs}

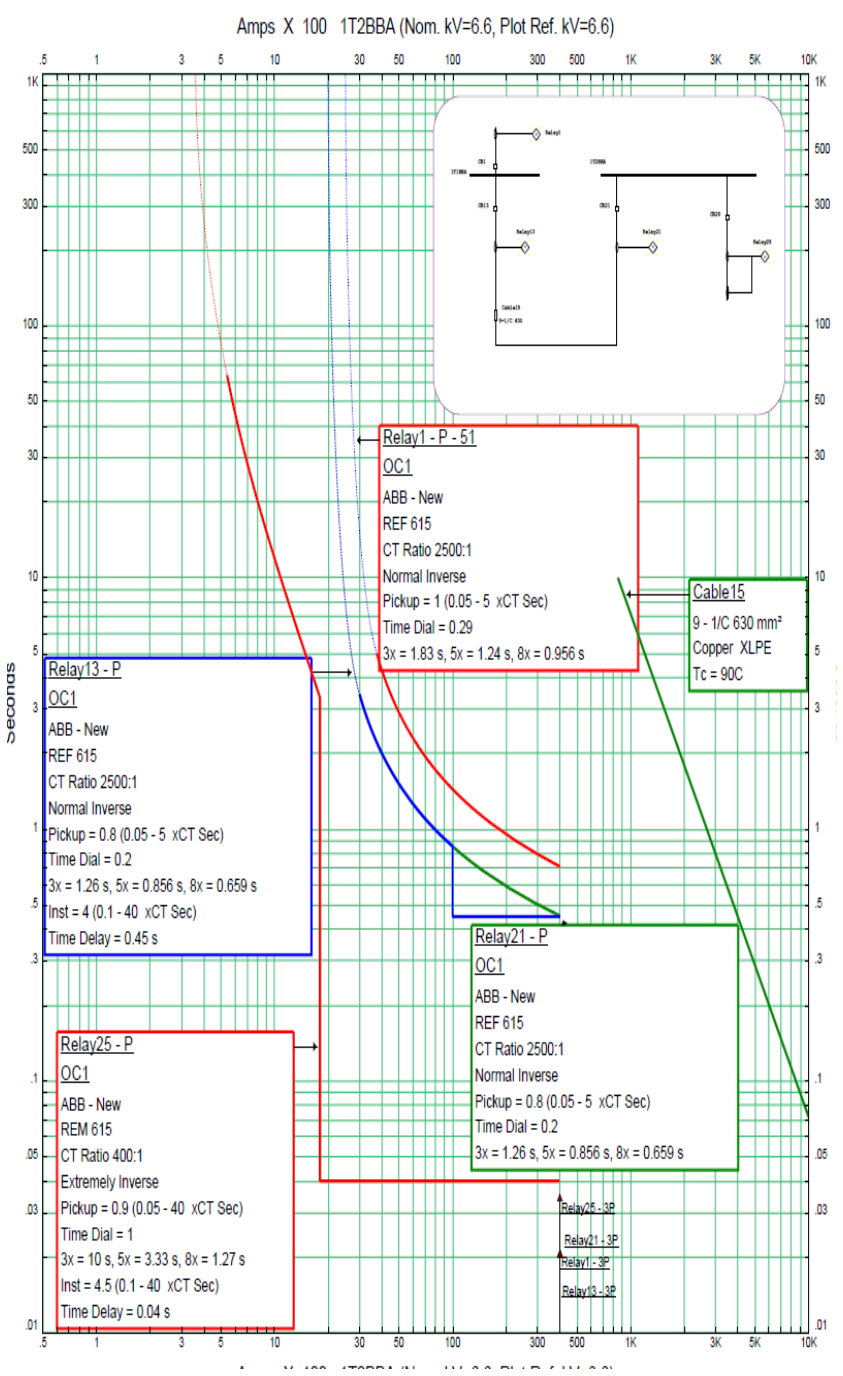

Real Time Distribution System

Relay Setting Table

Relay operating time table for a fault

\begin{tabular}{lcc}
\hline Relay & $\begin{array}{c}\text { Fault Current } \\
\text { In kA }\end{array}$ & $\begin{array}{c}\text { Operating Time } \\
(\mathrm{ms})\end{array}$ \\
\hline Relay 1 & 8.95 & 40 \\
Relay 2 & 11.6 & 40 \\
Relay 3 & 2.08 & 293 \\
Relay 4 & 2.6 & 287 \\
Relay 5 & 8.95 & 554 \\
Relay 6 & 11.8 & 576 \\
\hline
\end{tabular}

\section{Relay curve graphs}
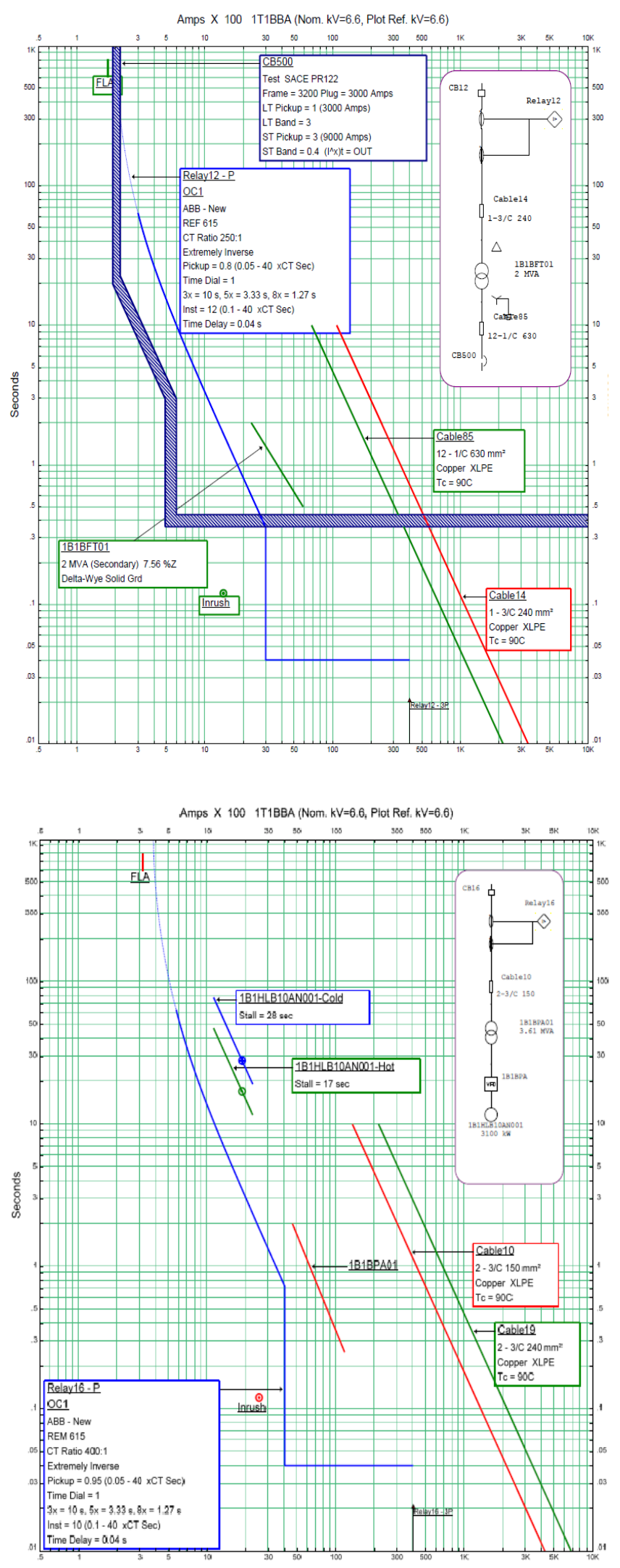


\section{Conclusion}

New Technique proposed in this paper for setting all Over Current (OC) relays in substations, process industries with cogeneration and distribution system with Embedded Renewable Generation provide significant advantage over the conventional way of relay settings. This technique is more suitable where there is a drastic change in the fault current based on the network topology and configuration. This technique is verified for setting the OC relays in IEEE 30 Bus system, Real time steel industry and a Real time distribution system with Embedded Renewable Generation. There is a significant reduction in fault clearing time which reduces the damage and enhance the stability. In addition, it also prevents all the maloperation of relays and nuisance tripping. Based on the above conclusions it is recommended to review all the relay settings of existing system while retrofitting or Annual maintenance.

\section{References}

1. Ojaghi M, Sudi Z, Faiz J. Implementation of full adaptive technique to optimal coordination of over current relays. IEEE Trans. Power Del. 2013 Jan; 28(1):235-244. doi:10.1109/TPWRD.2012.2221483.

2. PukarMahat, BirgitteBak-Jensen, ClausLethBak A. Simple adaptive over current protection of distribution systems with distributed generation. IEEE Trans on smart Grid. 2011 Sept; 2(3).

3. Urdaneta AJ, Perez LG, Restrepo H. Optimal coordination of directional over current relays considering dynamic changes in the network topology. IEEE Trans. Power Del. 1997 Oct; 12(4):1458-1464.

4. The electricity training association, in power system protection. New Delhi, India: Shankar's Book Agency PVT. Ltd., 2010; 2, First Indian Reprint.

5. Abdelaziz AY, Talaat HEA, Nosseir AI, Hajjar AA. An adaptive protection scheme for optimal coordination of over current relays. Elect. Power Syst. Res. 2002; 61(1):1-9.
6. Noghabi AS, Sadeh J, Mashhadi HR. Considering different network topologies in optimal over current relay coordination using a hybrid GA. IEEE Trans. Power Del. 2009 Oct; 24(4):1857-1863..

7. Noghabi AS, Sadeh J, Mashhadi HR. Optimal coordination of directional over current relays considering different network topologies using interval linear programming. IEEE Trans. Power Del. 2010 Jul; 25(3):1348-1854.

8. Urdaneta A.J, Pérez LG, Gómez JF, Feijoo B. González M. "Presolve analysis and interior point solutions of the linear programming coordination problem of directional over current relays. Elect. Power Energy Syst. 2000. 23: 819-825.

9. Tsien HY. An automatic digital computer program for setting transmission line directional Over Current relays. IEEE Transactions on Power Apparatus and Systems. 1964; 83:1048-1053.

10. Razavia F, Abyaneha HA, Al-Dabbaghb M, Mohammadia $\mathrm{R}$, Torkamanc H. A new comprehensive genetic algorithm method for optimal over current relays coordination. Electric Power Syst Res. 2008; 78:713-720. 2001; IEEE Recommended Practice for Protection and Coordination of Industrial and Commercial Power Systems. IEEE Standard 242.

11. Gokhale SS, Kale VS. Application of the Firefly algorithm to optimal over-current relay coordination. International Conference on Optimization of Electrical and Electronic Equipment (OPTIM). 2014 May 22-24; pp.150-154, doi:10.1109/OPTIM.2014.6850887.

12. Ukil A, Deck B, Shah V H. Smart distribution protection using current-only directional over current relay. Innovative Smart Grid Technologies Conference Europe (ISGT Europe). IEEE PES. 2010 Oct 11-13; pp.1-7, doi: 10.1109/ISGTEUROPE.2010.5638909.

13. Uthitsunthorn D, Pao-La-Or P, Kulworawanichpong $\mathrm{T}$. Optimal over current relay coordination using artificial bees colony algorithm. 8th International Conference on Electrical Engineering/Electronics, Computer, Telecommunications and Information Technology (ECTI-CON). 2011 May 17-19; pp.901-904, doi: 10.1109/ECTICON.2011.5947986. 